Estudios de Administración, vol. 7, N 1, 2000

\title{
The Determinants of the Choice of Preferred Providers among the Publicly Insured in Chile: an Empirical Analysis
}

\author{
Ricardo Henríquez $\mathrm{H}$.
}

Universidad de Chile

\begin{abstract}
This paper analyses the determinants of the choice of provider among the publicly insured in Chile. The focus is on the Preferred Provider System (PPS) where public insured can opt for a more consumer-oriented environment subject to a higher level of copayments. Using a model of expected utility gain we develop a logit analysis based on a large multipurpose survey, the Encuesta de Caracterización Socioeconómica Nacional, CASEN 1992 (National Survey for Socioeconomic Characterisation). We make use of several socio-economic, demographic and access variables in our econometric estimation. As a whole, our results adjust to the hypotheses formulated. Among others, individuals' income, the relative value of copayments, waiting time and zone of residence emerge as the most
\end{abstract}

* This paper, a product of my doctoral thesis, was first distributed as Working Paper 75 (April 2000), Departamento de Administración, Facultad de Ciencias Económicas y Administrativas, Universidad de Chile. I am most indebted to Professor Richard Disney (School of Economics, University of Nottingham) and Dorothe Bonjour, Ph.D (Economics Department, Queen Mary \& Westfield College, University of London) for their useful comments on earlier drafts. I also owe thanks to an anonymous referee. The usual disclaimer for remaining errors holds. 
relevant determinants in the decision process. The positive effect of income would indicate some degree of segmentation within the public system, while the impact of the relative value of copayments shows that user charges can act as an important deterrent for some individuals. The unexpected negative effect of waiting time, included in our estimation as a provider's attribute, would suggest certain level of captivity in the sense that some individuals have no real choices but purely public provision.

The result for zone of residence indicates that rural residents are less likely to choose preferred providers than urban residents. This result is explained by the spatial distribution of preferred providers who tend to cluster in urban areas.

Key words: preferred providers, public health insurance contribution, copayments. JEL Classification: I11, I18.

\section{Extracto}

En este artículo se analizan los determinantes de la elección de proveedores preferidos (preferred providers) bajo la modalidad de libre elección en el sistema de salud público chileno. Esta modalidad de atención, a diferencia de la modalidad institucional, permite a los beneficiarios públicos escoger tanto el médico como el lugar donde atenderse, sujetos a un régimen de copagos más elevados. Dada la naturaleza discreta (dicotómica) de la decisión, se utiliza un modelo logístico. La selección de una u otra alternativa depende de la ganancia de utilidad esperada. La estimación empírica está basada en la Encuesta de Caracterización Socioeconómica Nacional (CASEN) correspondiente a 1992. Un grupo importante de variables socioeconómicas, demográficas y de acceso son incluidas en el análisis. Entre otras, el nivel de ingreso del individuo, el valor relativo de los copagos, el tiempo de espera y la zona de residencia (urbano/rural), aparecen como los determinantes más relevantes en este proceso decisorio. El efecto positivo del ingreso indicaría cierto nivel de segmentación al interior del sistema público, mientras que el signo negativo del coeficiente asociado a los copagos relativos permitiría reconocer el efecto descincentivador de cargos monetarios más elevados sobre la demanda por proveedores preferidos. El efecto negativo y no esperado de tiempo de espera, incorporado como un atributo del proveedor, sugeriría algún grado de cautividad, en el sentido que algunos beneficiarios públicos no tendrían más opción que la atención institucional. Finalmente, el resultado para zona de residencia indica que aquellos individuos que 
viven en zonas rurales tienen menor probabilidad de acceder a proveedores adscritos a la modalidad de libre elección. Este resultado se explica fundamentalmente por la distribución espacial de dichos proveedores los cuales, por lo general, tienden a establecerse en zonas urbanas.

\section{Introduction}

In this paper we analyse the determinants of the choice of health care provider among the publicly insured in Chile. The focus is on the Preferred Provider System (PPS), fully described in the next section. We utilise regression analysis to examine individual's choice between purely public provision and provision through the PPS.

The choice of provider not only has implications in terms of waiting time and access to a more consumer-oriented environment, ${ }^{1}$ but also for the performance of the public system. ${ }^{2}$ By choosing preferred providers public insured free up resources for those who rely exclusively on public sector provision and, to some extent, alleviate the pressure on public health facilities, pressure that has increased along the time due to demographic changes and changes in the perception of individuals about the importance of their health status. The higher cost of preferred providers, however, imposes a limit to the percentage of public insured that takes this option. Furthermore, although since 1981 individuals can opt entirely out of public sector provision through private health insurance plans, the public health system still has to cope with the medical needs of more than two third of the Chilean population. In this context, our work has an important motivation: to explore the factors that influence individual's choice of health care providers in order to provide empirical evidence concerning the debate on future changes in the regime governing the provision of health services to the publicly insured.

\footnotetext{
${ }^{1} \mathrm{~A}$ consumer-oriented environment in the context of medical care can be associated with certain attributes mainly linked to private provision such as "hotel" services, choice of doctor and a greater level of information about the medical condition and its treatment.

${ }^{2}$ Even though the choice of preferred providers could also have an impact on the public funding for public provision, we focus this analysis exclusively on the provision side.
} 
The empirical analysis is based on the data contained in the fourth Encuesta de Caracterización Socioeconómica Nacional, CASEN 1992 (National Survey for Socioeconomic Characterisation). This multipurpose survey, which has been conducted by the Chilean government since 1985, is structured in 5 modules designed to collect information on several aspects of housing, education, health, employment and income across the thirteen regions of the country.

Among other matters, the health module provides information on the utilisation of medical services including both outpatient and inpatient medical care. ${ }^{3}$ Our analysis is based on outpatient events and, particularly, on general medical consultations. Data limitations precluded us from extending the analysis to examine inpatient events. Unfortunately, CASEN 1992 does not provide important details about hospitalisations and surgery (the principal inpatient services recorded). Individuals were only asked if they were hospitalised during the last three months, but the cause of the hospitalisation or if they were hospitalised in a shared or single ward was not reported. Similarly, individuals were asked if they had a surgery during the last three months, but the specific type of surgery was not registered. Thus, the information on these events was too general to be used in our analysis. ${ }^{4}$

The organisation of the paper is as follows. Section 2 presents a detailed description of the preferred provider system. In section 3 we discuss the expected utility gain that a public insured could obtain by choosing preferred providers. In section 4 we describe the binary choice model on which the econometric estimation is based. Section 5 describes the data and defines the variables included in the estimation. In section 6 we present and discuss the results. Here, we also present a sensibility analysis that provides additional information on the magnitude of the impact of a change in each of the explanatory variables on individuals'

${ }^{3}$ CASEN 1992 collected information for preventive care, general consultations, consultations to specialists, casualty consultations, dental attention, laboratory exams, surgery, hospitalisation, and delivery medical services.

${ }^{4} \mathrm{An}$ important factor included in the analysis was the monetary cost of medical attention. Given the lack of information relative to the specific type of these particular medical events (hospitalisations and surgery), it was not possible to determine their monetary cost. 
choice. Section 7 concludes.

\section{The preferred provider system}

A Preferred Provider System (PPS) was introduced in Chile in 1968 to allow white-collar workers (public and private employees, active or retired) and their dependent to choose doctors and hospitals while paying part of the cost. ${ }^{5}$ This system came to complement the benefits provided by the National Health Service created long before in 1952. However it was not until 1985 that the PPS was fully consolidated through its extension to all workers independently of their category or working status. ${ }^{6}$ Since that time all individuals contributing to the public insurer, the National Health Fund (NHF), can obtain medical care through the public facility network (purely public provision) composed of public hospitals and public health centres, or they can use providers that have an agreement with the NHF (preferred providers). Any doctor or private health facility, including private hospitals, private clinics and private surgeries, can sign a contract with the NHF to work as preferred providers subject to certain regulations. ${ }^{7}$

The only legal requirement to access the benefits provided by the NHF is the percentage of taxable income that must be spent, as a minimum, on health insurance (hereafter contribution). Since 1986 this percentage has stood at 7 percent and currently the number of NHF's insured reaches 8.6 million (almost 61 percent of the Chilean population). All those contributing can choose between the two alternatives at any time. Public

\footnotetext{
${ }^{5}$ The operation of the system was relatively simple: white-collar workers were entitled to buy a voucher (whose value incorporated a government contribution) with which they could freely choose both the doctor and the health facility where to be attended. Since then, the operation of the system has suffered minor changes. In essence, it remains the same.

${ }^{6}$ As part of the social security system reform process initiated at the end of the 1970's, the Labour Plan eliminated the differences between blue-collar and white-collar workers. Currently all categories of employees are called workers.

${ }^{7}$ Public hospitals are also allowed to provide health services under the preferred provider system. A typical service offered is accommodation in single and shared wards.
} 
beneficiaries who do not pay contributions only have access to purely public provision. In principle, the health care entitlement is the same for all public insured, with the exception of the value of any additional copayment. ${ }^{8}$

Figure 1 provides a simple sketch to show how the contribution, copayments and providers interact within the public health system. Individuals in need are exempt from the legal contribution and copayments while receiving free health care through the public facility network. Salaried employees and pensioners contributing 7 percent of their taxable income can choose between purely public provision or provision via preferred providers. If the first alternative is chosen, an additional copayment according to income must be made. ${ }^{9}$ If the second option is chosen, copayments depending on the rating of the preferred provider apply. The rating in this latter case is associated to one of the three subsidised price levels defined by the NHF. Therefore, it follows that the agreement between preferred providers and the NHF is essentially an agreement on prices. ${ }^{10}$ Whatever be the option chosen, the NHF makes a differentiated contribution to help public insured to defray the cost of the medical services required.

\section{Figure 1}

Contribution, copayments and providers in the public health system

$\begin{array}{llll}\text { Population group Contribution } & \text { Copayment } & \text { Provider }\end{array}$

\begin{tabular}{l}
$\begin{array}{c}\text { Those in } \\
\text { need }\end{array}$ \\
\cline { 2 - 2 } \\
Insured free of charge no copayment \\
${ }^{8}$ Copayments are defined as the percentage of the cost of each health servide to \\
${ }^{9}$ Public insured are classified in four income groups: A, B, C, or D (see Table A \\
be covered by the insured. \\
in the Appendix for income ranks in 1992). Individuals in income group A (indigents) do \\
not contribute and do not make copayments. Individuals in income group B (low-income \\
level) must contribute but do not make copayments. Individuals in income groups C and D \\
must contribute and make copayments (in 1992 copayments were of 25 and 50 percent \\
respectively). Primary health care is free of charge for all public insured independently of \\
their income classification. \\
${ }^{10}$ Under the preferred provider system public hospitals are restricted to charge the \\
lower price level defined by the National Health Fund.
\end{tabular}




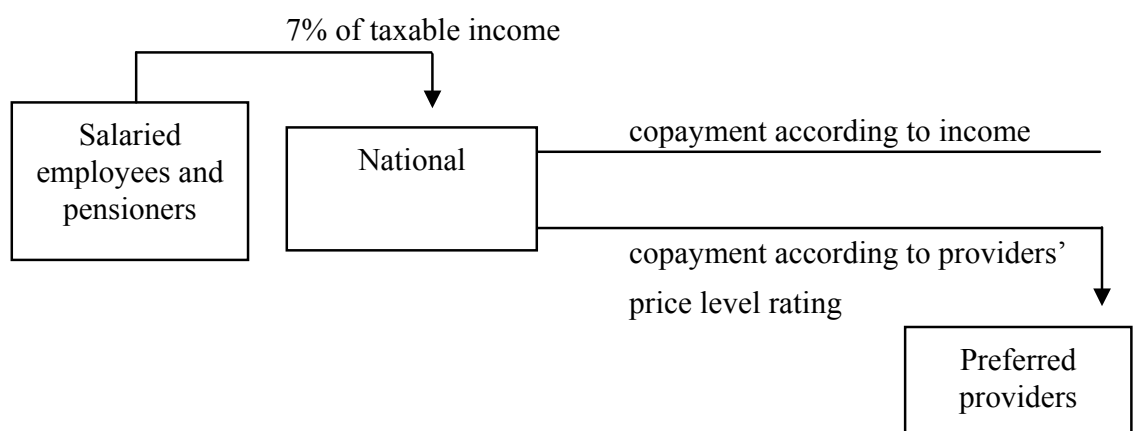

The different structure of copayments under both systems is expected to reflect the differences in costs as well as the ability to pay of those publicly insured. It can be understood by using a simple numerical example. Let us then consider the case of general medical consultations and the associated price and copayment structure found under purely public provision and preferred providers, respectively. ${ }^{11}$ The figures and percentages used correspond to those prevalent in 1992 and are expressed in Chilean pesos (Ch.\$) in Table $1 .^{12}$

Table 1

Structure of copayments for general medical consultations

\begin{tabular}{|c|c|c|c|c|}
\hline PURELY PUBLIC PROVISION & \multicolumn{4}{|c|}{ General Medical Consultation } \\
\hline \multirow{2}{*}{ Income groups } & \multirow{2}{*}{$\begin{array}{l}\text { Price } \\
(\mathrm{Ch} . \$)\end{array}$} & \multicolumn{2}{|c|}{ Copayment } & \multirow{2}{*}{$\begin{array}{c}\text { NHF contribution } \\
\text { Ch.\$) }\end{array}$} \\
\hline & & $(\%)$ & $(\mathrm{Ch} . \$)$ & \\
\hline A & 1000 & 0 & 0 & 1000 \\
\hline $\mathrm{B}$ & 1000 & 0 & 0 & 1000 \\
\hline $\mathrm{C}$ & 1000 & 25 & 250 & 750 \\
\hline $\mathrm{D}$ & 1000 & 50 & 500 & 500 \\
\hline PREFERRED PROVIDER & \multicolumn{4}{|c|}{ General Medical Consultation } \\
\hline Price level rating & $\begin{array}{l}\text { Price } \\
(\mathrm{Ch} . \$)\end{array}$ & \multicolumn{2}{|c|}{$\begin{array}{c}\text { Copayment } \\
\text { (Ch.\$) }\end{array}$} & $\begin{array}{l}\text { NHF contribution } \\
\text { (Ch.\$) }\end{array}$ \\
\hline I & 2200 & \multicolumn{2}{|c|}{880} & 1320 \\
\hline
\end{tabular}

${ }^{11}$ Each year the Ministry of Finance, in conjunction with the Ministry of Health, defines the price of the medical services as well as the parameters and criteria to calculate the value of copayments. dollar.

${ }^{12}$ The average observed exchange rate in 1992 was of Ch.\$362.58 per US\$ 1 


\begin{tabular}{|c|c|c|c|}
\hline II & 2350 & 1030 & 1320 \\
\hline III & 2750 & 1430 & 1320 \\
\hline
\end{tabular}

The top half of Table 1 shows us the price and copayments for a medical consultation under purely public provision. A price of Ch. $\$ 1000$ is the base to calculate the copayment according to income. Those in need (income group A) and those on low-income (income group B) are not charged. Salaried employees in income groups $\mathrm{C}$ and D are subject to a respectively increasing percentage of copayment. For all groups the NHF contributes with the difference between the cost of the service and the value of the copayment, but the contribution decreases as we move from income group A (or B) to income groups C and D.

The selection of preferred providers, on the other hand, implies the higher prices and copayments detailed in the bottom half of Table 1. The three different prices for medical consultation reflect the price level rating predetermined by the NHF. In this case, public insured receive a fixed contribution independently of the rating of the preferred provider. Thus, the percentage of copayment increases with price.

However, the relative cost of choosing the preferred providers "route" falls as income increases. High-income individuals can obtain a greater access to preferred providers because the copayment structure reduces the relative cost they face proportionally more than for lowincome individuals. In other words, the subsidy (contribution) provided by the government tends to benefit more those on high-income than those on low-income. Figure 2 shows this fact.

Part (a) in Figure 2 describes copayments for medical consultations under preferred providers (see bottom half of Table 1). In this case, copayments are independent of income and, therefore, a horizontal line is drawn at Ch.\$1430, Ch. $\$ 1030$ and Ch.\$880, respectively. Part (b) shows the copayment level according to income classification (see top half of Table 1). As we previously saw, individuals in income groups $\mathrm{A}$ and $\mathrm{B}$ are exempt from copayments while those in income groups $\mathrm{C}$ and D must make copayments of Ch.\$250 and Ch.\$500, respectively. Finally, part (c) shows the relative cost of choosing preferred providers [difference between (a) and (b)]. Clearly, the relative cost of individual's choice varies depending on the income classification. Thus, the relative cost of medical 
consultations for those in income groups A and B corresponds to the total cost shown in part (a). Conversely, public insured classified in income groups $\mathrm{C}$ and $\mathrm{D}$ face a relative cost that is a decreasing percentage of the total cost presented in part (a).

From the comments above, the relative cost of medical consultations should play an important role in public insured choice and, accordingly, individuals should carefully examine the benefits and costs associated to their decision.

\section{Figure 2}

Relative cost of medical consultations: difference between copayments under preferred providers and purely public provision by income groups.

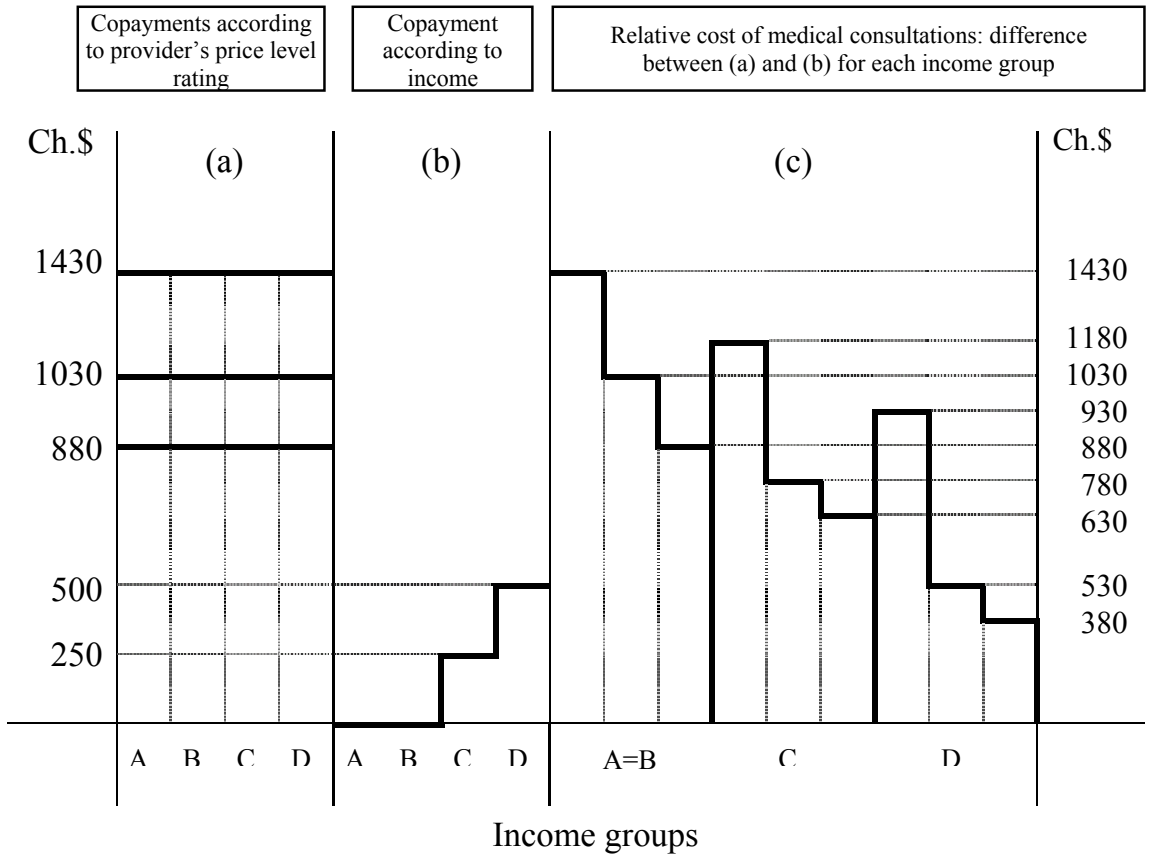

\section{Expected utility gain from choosing preferred providers}

The concept of expected utility gain has been applied to many economic decisions. For example, it has been used to explain whether to purchase a 
house or to rent, whether to purchase supplementary private insurance, whether to use a bus, train or own car as transport mode, etc. This approach suggests that individuals weigh up both the expected benefits and the expected costs associated with the options available. In other words, individuals maximise the expected utility gain. Here we use the same idea to analyse the choice of preferred providers.

The benefits of choosing the preferred provider "route" can be derived from two different sources: access to medical care in a more consumer-oriented environment and reduced waiting time. The attributes of a more consumer-oriented environment essentially imply better "hotel" services, choice of doctor and greater information about the medical condition and its treatment. The utility put on these consumer-oriented attributes may be a function of the desire for privacy and/or information [Propper (1989) p.780]. The difference in the quality of treatment per se is likely to be fairly small, as consultants concurrently work as preferred providers and as employees of the state while nursing and paramedical staffs are trained in the public sector. If the attributes associated with what we called a consumer-oriented environment are assumed to be normal goods, we could expect that high-income individuals were more prone to demand preferred providers. Unfortunately, these attributes are difficult to measure and, consequently, to model [Hopkins and Kidd (1996) p.1624].

On the other hand, to see why a reduced waiting time can benefit individuals, it is necessary to examine the implications of the rationing of public sector services. The rationing of services in public health facilities takes two forms: rationing by queue ${ }^{13}$ and rationing by waiting list. These two forms of time rationing impose a cost on individuals (or their family) via two dimensions involving the demand for medical care, respectively: the opportunity cost of time and the expected improvement in health status. According to Propper (1989), queuing in person clearly has an opportunity cost. In contrast, it has been suggested [Lindsay and Feigenbaum (1984)] that waiting on a list per se has no opportunity cost. ${ }^{14}$

${ }^{13}$ In Chile, waiting time is particularly high in public primary health care facilities. Scarpaci (1988) in his study carried out in a poor urban area of Santiago, the capital, found that individuals had to wait, on average, 4.6 hours to see a doctor in a public health centre.

${ }^{14}$ Following Propper (1989 p.779-780), this argument, which is open to debate, basically assumes that having to wait for medical treatment does not necessarily prevent 
Rather the cost of waiting on a list is associated with the likelihood that the medical problem may worsen during the waiting period with associated uncertainty about the timing of medical attention. In what follows, however, and given the nature of the medical events considered in our analysis (general medical consultations), we will focus only on the effect of queuing in person on individuals' utility.

Ceteris paribus, the expected utility gain from bypassing the rather long queue found in the public sector should be greatest for those who place the highest value on time. Accordingly, it would be reasonable to expect a higher value of time for those employed rather than unemployed and those with higher incomes rather than with lower incomes. This presumption should therefore provide a justification for including individuals' income and employment status in the empirical estimation.

In addition, the benefits of jumping the public sector queue can differ not only according to income or employment status, but also can vary with age, sex and education. For instance, the pattern of earnings of individuals along their life cycle is generally described as dome-shaped function of age. Basically this means that earnings (income) increase with age (a period with a higher opportunity cost) until certain point where individuals usually experience a reduction in income as they get retired and become pensioners (a period with a relatively lower opportunity cost). ${ }^{15}$ According to this pattern, one could expect that individuals in their more productive years were more prone to seek medical attention from preferred providers. By the same token, one could also expect that older individuals with a lower opportunity cost were less worried about queuing and, therefore, considering purely public provision as a satisfactory alternative. However, as age increases medical needs also increase and individuals tend to make a greater use of medical services. In this context, the perspective of queuing long hours to be attended should not be very attractive for the elderly.

the demander of medical care from carrying out some work or other activities. However, by definition, an individual on a waiting list is in a less good state of health than his normal state. Being ill and waiting on a list may both decrease the utility of some uses of time and/or prevent the individual from undertaking all his usual activities. This would suggest that waiting on a list has some positive opportunity cost for the demand of medical care.

${ }^{15}$ The perspective of a lower income at the time of retirement is a common fact for most of the pensioners in Chile. 
Differences in medical needs are also important by sex. Many studies have shown that females make more consultations than males [Lewis and Lewis (1977), Sindelar (1982), Leopold and Langwell (1978)]. This tendency has been explained, primarily, as the result of biological differences and biological events affecting only females, such as pregnancy and maternity. ${ }^{16}$ These factors determine that females spend more time than males do in consulting doctors (sometimes for themselves or for their children) and, therefore, they should value more than males the shorter time required to get medical attention from preferred providers.

On the other hand, the positive relation between education and income [van der Ven and Van Praag (1981)] indicates that more educated individuals should have a higher opportunity cost of time. Therefore, one would expect that more educated individuals were in a better position to value the possibility to jump the queue present under purely public provision. At the same time, more educated individuals may be better equipped to appreciate the attributes of the more consumer-oriented attention offered by preferred providers.

The costs involving the decision to choose preferred providers are basically related to access. In this context, an important restriction is given by the higher value of copayments. A higher copayment, which in practical terms implies a higher out-of-pocket outlay, could outweigh the benefits of a more consumer-oriented environment or the less timeconsuming access to preferred providers and induce individuals to select the less expensive option represented by purely public provision, ceteris paribus. $^{17}$

The possibility of substitution due to the higher cost of medical attention under preferred providers should become more probable after considering that the decision of seeking medical care is usually taken in the context of the family rather than in isolation. In this sense, one might expect that individuals belonging to families with more children were less likely to choose preferred providers. The restriction on resources available as the size of the family increases could affect the possibility of each

\footnotetext{
${ }^{16}$ According to Sindelar (1982), this tendency persists even after controlling for gynaecological and obstetrical care and severity of illness.

${ }^{17}$ This could be the case even though preferred providers allow public insured to get private medical attention at subsidised prices.
} 
family member to access providers that imply a higher expenditure. In this case, a higher number of children in a household could contribute to this fact. ${ }^{18}$ Conversely, ceteris paribus, individuals belonging to families with more adults with positive income could be relatively more likely to demand preferred providers.

Finally, another restriction to access is determined by the location of preferred providers. Even though the national coverage of public provision through the extended network of public health facilities ensures access to most of the population, the access to preferred providers is restricted by their location. In fact, preferred providers tend to be located in urban areas where most of the population is concentrated. This fact implies that, on average, individuals living in rural areas must incur in a higher cost to access preferred providers, mainly due to travelling costs.

\section{Choice model}

We have described a situation where public insured face two alternatives of medical care and they must choose one. Thus, the decision becomes dichotomic. ${ }^{19}$ The nature of the decision, therefore, suggests the use of a binary choice model where each observation is treated as a single draw from a Bernoulli distribution (binomial with one draw). Our econometric estimation is based on an extensively applied binary choice model, the logit, where parameters can be estimated using maximum likelihood procedures.

It is assumed the existence of a binary variable $y_{i j}$ that takes the value one if individual $i$ opts for preferred providers (indexed as alternative $j=1$ ) and zero if individual $i$ opts for purely public provision (indexed as alternative $j=0$ ). Thus,

$$
y_{i j}=1 \quad \text { if } j=1 \text { (preferred providers) }
$$
dependent.

${ }^{18}$ The number of children is used in our analysis as a proxy for the number of

${ }^{19}$ Strictly speaking individuals face one alternative under purely public provision and three price levels (alternatives) within the preferred provider option. However, as we explain later in section 5.B., data restrictions constrain us to just one price level under preferred providers so that the options reduce effectively to two. 


$$
y_{i j}=0 \quad \text { if } j=0 \text { (purely public provision) }
$$

Writing the probability hat individual $i$ chooses alternative 1 as, $P_{i l}=$ $\operatorname{Pr}\left[y_{i l}=1\right]$ then,

$$
\sum_{j=0}^{1} y_{i j}=\sum_{j=0}^{1} P_{i j}=1
$$

Assuming a sample of $n$ individuals, the likelihood function is given by,

$$
\ell=\prod_{i=1}^{n} P_{i 0}^{y_{i 0}} P_{i 1}^{y_{i 1}} .
$$

Taking logs on (2) we get the following log-likelihood function,

$$
\ln \ell=\sum_{i=1}^{n}\left(y_{i 0} \ln P_{i 0}+y_{i 1} \ln P_{i 1}\right)
$$

The model behind (3) is made into a behavioural one by relating the selection probabilities to attributes of the alternatives in the choice set and the attributes of the individual making the choice. Such a model can be motivated by assuming that individuals maximise utility and that the utility function is stochastic; that is, a random utility model [due to McFadden $(1981) .^{20}$

Assuming linearity and denoting $U_{i 0}$ and $U_{i 1}$ the utility derived by individual $i$ from demanding purely public provision and preferred providers, respectively; $x_{i}$ a vector of individual's attributes, and $z_{i 0}, z_{i 1}$ vectors of providers' attributes as perceived by individual $i$, we can write,

${ }^{20}$ According to Maddala (1983), the stochastic nature of the utility function emerges from the assumption that consumers are rational in the sense that they make choices that maximise their perceived utility subject to constraints on expenditures. However, there are many errors in this maximisation because of imperfect perception and optimisation, as well as the inability of the analyst to measure exactly all the relevant variables. 


$$
\begin{aligned}
& U_{i 0}=\alpha_{0}+x_{i}^{\prime} \delta_{0}+z_{i 0}^{\prime} \gamma+e_{i 0}, \\
& U_{i 1}=\alpha_{1}+x_{i}^{\prime} \delta_{1}+z_{i 1}^{\prime} \gamma+e_{i 1} .
\end{aligned}
$$

The observed choice between (4) and (5) reveals which alternative provides the greater utility, but not the unobservable utilities. The demand function for a particular alternative is the probability that the utility derived from it is higher than the utility derived from the other. Thus, the observed indicator $y_{i j}=1$ if $U_{i 1}>U_{i 0}$, and the observed indicator $y_{i j}=0$ if $U_{i l}<U_{i 0}$. Therefore, the probability that $y_{i j}$ be equal 1 will be given by,

$$
\begin{aligned}
& \operatorname{Pr}\left(y_{i j}=1\right)=\operatorname{Pr}\left(U_{i 1}>U_{i 0}\right) \\
& =\operatorname{Pr}\left[\left(e_{i 0}-e_{i 1}\right)<\left(\alpha_{1}-\alpha_{0}\right)+x_{i}^{\prime}\left(\delta_{1}-\delta_{0}\right)+\left(z_{i 1}-z_{i 0}\right)^{\prime} \gamma\right] \\
& =F\left(w_{i}^{\prime} \beta\right)
\end{aligned}
$$

where $F$ represent the cumulative distribution function for the error term $e_{i}$, and with $w_{i}=\left[1, x_{i}{ }^{\prime},\left(z_{i 1}-z_{i 0}\right)^{\prime}\right], \beta^{\prime}=\left[\left(\alpha_{1}-\alpha_{0}\right),\left(\delta_{1}-\delta_{0}\right)^{\prime}, \gamma^{\prime}\right]$.

The logit model follows from the assumption that the cumulative distribution function of $e_{i}$ is the logistic. Then, the probability that $y_{i j}$ be equal 1 is written as,

$$
\operatorname{Pr}\left(y_{i j}=1\right)=\frac{\exp \left(w_{i}^{\prime} \beta\right)}{1+\exp \left(w_{i}^{\prime} \beta\right)}
$$

It must be noticed that in (4) and (5) the coefficients of vector $x_{i}$ were allowed to vary between alternatives. Since only differences in utility matter, if any explanatory variable is equal between alternatives it will not influence individual choice. This means that the variable in question does not contribute to the explanation of why one particular alternative is chosen and its coefficient can not be estimated. Accordingly, if the coefficients of those variables reflecting individuals' attributes, which do 
not vary between alternatives, are to be identified, they must be allowed to have differential impacts upon the probability of choosing one alternative rather than another, i.e., the coefficient vector must be made alternativespecific.

Following the discussion of section 3., we used three groups of explanatory variables in the empirical analysis. The first group accounts for individuals' demographic and socio-economic attributes as described by age, sex, education, employment status and income. The second group is composed of two variables reflecting individuals' family composition: number of children and number of adults in the household. The third group accounts for individual's access to medical attention. We include here individuals' zone of residence, the relative cost of medical consultations and waiting time. A description of the data utilised in the estimation and the definition of each variable are presented in the next section.

\section{Data and variable definitions}

\section{A. The data}

The data set used in the estimation was drawn from the fourth Encuesta de Caracterización Socioeconómica Nacional, CASEN 1992 (National Survey for Socioeconomic Characterisation). The Ministry of Planning of Chile has carried out this multipurpose survey since 1985 with a periodicity of two years. CASEN 1992 gathered information from a stratified sample of 35,948 households (143,459 individuals). The sampling unit was the household, although the survey record data were at the individual level. Any household member aged 18 or older was eligible to act as a spokesperson for all household members. Individuals were linked according to their relationship with the head of the household. The capacity to link individual records is important as the decision to seek medical care from one alternative or another is more likely to be taken within the family rather than in isolation. As Sindelar (1982) pointed out, although many studies analyse the individuals' maximisation process without considering the family, it seems to be more appropriate to analyse their behaviour in the family context. 
The survey sample was designed to have representation at national, regional, provincial and municipal level. The country was divided into 138 municipal districts reflecting two strata, urban and rural. Information was collected using five modules: housing, education and training, health, employment, and income.

The health module, among other aspects, recorded information on both outpatient and inpatient health services utilisation from the 32,682 household members who reported having suffered an illness or accident during the three months preceding the interview. The fact that only ill individuals were considered is consistent with the argument of Akin et al. (1985) that if a combined sample of both healthy and sick people is used, it is implicitly assuming that illness is unrelated to demand for medical care.

Among the group who suffered and illness or accident only 82.46 percent were reported to have sought medical care, that is, 26,950 individuals (11,646 males and 15,304 females). Public insured accounted for 68.59 percent of this figure (18,485 individuals). The remaining percentage corresponded to individuals insured through private pre-paid health insurance plans, through social security institutions belonging to the armed forces, and others.

We focused the analysis of the choice of preferred providers by public insured in the particular case of general medical consultations. This type of outpatient event is defined by CASEN 1992 as physician visits where individuals have not been referred by another doctor. This means that individuals voluntarily decide to visit a doctor (patient initiated visit). The importance of this characteristic is that individuals make an independent choice, which is not influenced or induced by the doctor, like follow-up visits. ${ }^{21}$ In this last case, if the first of a series of visits was made to a preferred provider, the most probable is that a follow-up visit be made to the same preferred provider or, maybe, to another but also working within the preferred provider system. ${ }^{22}$

\footnotetext{
${ }^{21}$ Hershey et al. (1975) present a detailed discussion about the implications of using patient initiated visits or follow-up visits, among other measures of utilisation, to study individuals' utilisation of medical care.

${ }^{22}$ By using general medical consultations the possible bias on individuals' choice produced by the effect of an induced demand is, in some extent, mitigated.
} 
A related health service, preventive controls, was not included in the analysis. Although it would be possible to argue that preventive controls share similar characteristics to general medical consultations and that, therefore, they should be included, the concept of preventive controls utilised in CASEN 1992 is directed to capture the utilisation made by specific population groups: individuals facing chronic diseases (like diabetes and hypertension), new-borns, children, and pregnant women. ${ }^{23}$ Certainly, this restricted use of the concept excludes medical checkups, which are normally associated with the voluntary decision of an individual to control his health state, and which is not induced by doctors.

In this context, the sample of 18,485 ill public insured that sought medical care was reduced to those who made a general medical consultation, that is, 9,540 individuals (4,082 males and 5,458 females). Two further selections were considered: on the one hand, not every public insured can freely choose providers (see section 2.) so the sample was constrained to that fraction of public insured in income groups B, C and D. On the other hand, CASEN 1992 includes as potential providers public health facilities like Servicios de Atencion Primaria de Urgencia, SAPUS (Primary Health Care Emergency Services) and Consultorios de Especialidades (Public Clinics for Specialities), which are not institutionally related with the provision of general medical consultations. The survey also includes health facilities belonging to the Armed Forces where the access is restricted to their members (and relatives). After deletion of the observations that did not correspond to income groups $\mathrm{B}$, $\mathrm{C}$, and $\mathrm{D}$ and after excluding those health facilities not related with general medical consultations or where the access was restricted, the sample reduced to 4,481 individuals (1,966 males and 2,515 females). Finally, given that we only worked with the adult population (individuals aged 15 or older), the sample was reduced to 1,904 individuals (757 males and 1,147 females).

\footnotetext{
${ }^{23}$ From the point of view of public health, individuals belonging to these groups present a higher biomedical risk. Therefore, the health system encourages them to demand medical attention on a regular basis, independently if they feel themselves healthy.
} 


\section{B. Variable definitions}

A description of the variables and the defined default group in the model are reported in Table 2. The dependent variable, that we called the "option", is defined as a binary one taking the value 1 if a preferred provider was chosen and 0 if purely public provision was chosen. Given that CASEN 1992 did not include a specific question to identify, explicitly, the choice made by each individual, the dependent variable was built combining the responses to three questions included in the health module: income group under public insurance, type of health facility chosen, and the way in which individuals paid for the medical attention received. With respect to the first question, and as we pointed out before, we only considered observations corresponding to public insured and, particularly, public insured classified in income groups $\mathrm{B}, \mathrm{C}$, and D. We matched each individual of this sub-sample with his choice relative to one of the following five health facilities: public hospitals and public health centres associated with purely public provision; and private hospitals, private clinics and private health centres, associated with preferred providers. We controlled this match by relating each public insured with his response about the way in which he paid for the attention received; that is, either according to income classification or according to providers' price level rating.

Table 2

Description of variables

\begin{tabular}{|l|l|}
\hline Dependent variable: & \\
\hline Option & $\begin{array}{l}\text { Binary variable (dummy): } 1=\text { preferred providers, } 0=\text { purely } \\
\text { public provision. }\end{array}$ \\
\hline Explanatory variables: & Age of the individual (in years). \\
\hline Age & Binary variable (dummy): $1=$ female, $0=$ male. \\
\hline Gender & $\begin{array}{l}\text { Set of five binary variables (dummies) for the highest } \\
\text { educational level achieved: no education, primary school, } \\
\text { primary and secondary school, professional training and } \\
\text { university degree. The default is no education. }\end{array}$ \\
\hline Employment status & Binary variable (dummy): $1=$ employed, $0=$ otherwise. \\
\hline
\end{tabular}




\begin{tabular}{|l|l|}
\hline Income & $\begin{array}{l}\text { Individuals' monthly monetary income (Chilean pesos). } \\
\text { Corresponds to the aggregation of several income concepts, } \\
\text { including earnings from the principal job, pensions and } \\
\text { public subsidies. }\end{array}$ \\
\hline Number of children & Number of household' members aged 15 or less. \\
\hline Number of adults & $\begin{array}{l}\text { Number of household' members aged older than 15 with } \\
\text { income greater than zero. }\end{array}$ \\
\hline Zone of residence & $\begin{array}{l}\text { Geographic binary variable (dummy): 1=urban zone, 0=rural } \\
\text { zone. }\end{array}$ \\
\hline $\begin{array}{l}\text { Relative cost of medical } \\
\text { consultations }\end{array}$ & $\begin{array}{l}\text { Difference in the value of copayments between preferred } \\
\text { providers and purely public provision measured in Chilean } \\
\text { pesos. }\end{array}$ \\
\hline Waiting time & Waiting time at public health centres (in minutes). \\
\hline
\end{tabular}

Three groups of explanatory variables reflecting individuals' attributes, individuals' family composition and individuals' access to medical care were used in the econometric analysis. Among the first group, we included age, sex, education, employment status and income. Age entered the model as a continuous variable recording individuals' age in years. Only individuals aged 15 or older were considered because the analysis was constrained to the adult population. Sex was codified by a binary variable taking the value 1 for females and 0 for males.

Education entered the estimation as a set of five binary variables $(0,1)$ accounting for the highest level of education achieved. Five levels of education were considered: no education, primary school, primary and secondary school, professional training and university degree.

Employment status was defined as a binary variable taking the value 1 if employed and 0 otherwise. Income, a continuous variable, reflects individuals' monthly monetary earnings. The monetary income in CASEN 1992 is composed of several sources including earnings from the principal job, state subsidies and pensions.

The second group of variables was intended to capture individuals' family composition. We included the number of children (individuals aged less than 15) and the number of adults (individuals older than 15 with income greater than zero).

Three variables were used to describe individuals' access to medical attention: zone of residence, relative cost of medical consultations and waiting time. By including zone of residence we sought to identify differences in access among individuals living in urban and rural areas. 
This variable was defined as a dummy taking the value 1 if the individual resided in an urban area and 0 if the individual resided in a rural area.

The relative cost of medical consultations and waiting time reflect providers' attributes and were included to capture individuals' access to effective care. The relative cost of medical consultations was measured as the difference in the value of copayments between preferred providers and purely public provision (see Figure 2). ${ }^{24}$ Basically, we matched each individual with the copayment that should have been made under both alternatives (purely public provision and preferred providers).

The figures to construct the relative cost of medical consultations were obtained directly from the National Health Fund (CASEN 1992 did not ask the interviewed about the value of the copayment made or the price level rating of the preferred provider visited). In this context, and from the perspective of patients, the relative cost of medical consultations was exogenous. Using this approach the endogeneity problem that usually arises when price information is collected from respondents was avoided.

However, an additional point had to be solved. Considering that individuals under the preferred provider option can choose among three price levels and no information in this respect was recorded, we assumed price level rating III for each observation. This assumption is supported by the fact that nearly 70 percent of all preferred providers are enrolled in that level.

No specific assumption was made for the purely public provision option because given the income classification and the value of the medical consultation is possible to assign each individual an exact value of copayment.

Finally, to capture the effect of waiting time on individuals' choice, we utilised the reported waiting time at public health centres. This was possible because CASEN 1992 asked individuals about their experiences with public health centres in terms of waiting time (queuing for medical attention). The relevance of this question is given by the fact that most of the general medical consultations provided under purely

${ }^{24}$ Certainly, the value of copayments only represents the monetary cost of medical consultations. Travel time and waiting time also represent important costs, which can be even more relevant for some individuals when the out-of-pocket payments for medical care are low (see Acton, 1975). 
public provision are delivered at public health centres, the port of entry to the public health system. Waiting time was recorded in minutes and nearly 82 percent of the interviewed with non-missing records reported to have waited more than 60 minutes. However, many respondents included in the remainder 18 percent are believed to misreport the waiting time by reporting only the minutes the doctor spent in checking them. The Ministry of Health of Chile recommends public doctors to spend, as a minimum, 15 minutes per patient at public health centres, which proceeds from a technical norm of four patients per hour. Certainly, this does not correspond to waiting time. Waiting time is related to the time spent in the queue to collect the ticket with the number of attention (usually the most important component of total waiting time) plus the time waited to be effectively seen by the doctor. Therefore, we assigned to all those who reported a waiting time of less than 15 minutes the mean waiting time of their respective municipal district (given that public health centres are organised at local level). Descriptive statistics of the sample are given in Table 3.

Table 3

Descriptive statistics $(N=1,904)$

\begin{tabular}{|l|c|c|c|}
\hline VARIABLES & \% OF OBS. $=1$ & MEAN & ST.DEVIATION \\
\hline Dependent variable: & & & \\
\hline Option & 41.07 & & \\
\hline Explanatory variables: & & & \\
\hline Age & & 49.88 & 19.02 \\
\hline Gender & 60.24 & & \\
\hline No education & 10.29 & & \\
\hline Primary school & 56.56 & & \\
\hline Primary and secondary school & 28.46 & & \\
\hline
\end{tabular}




\begin{tabular}{|l|r|r|r|}
\hline Professional training & 1.57 & & \\
\hline University degree & 3.09 & & \\
\hline Employment status $^{\text {Income }}{ }^{\text {a }}$ & 36.71 & & \\
\hline Number of children & & $54,820.51$ & $92,867.83$ \\
\hline Number of adults & & 1.00 & 1.19 \\
\hline Zone of residence $^{\text {Relative cost of medical consultations }}{ }^{\text {a }}$ & 67.96 & 1.96 & 1.07 \\
\hline Waiting time $^{\text {b }}$ & & $1,276.48$ & 270.78 \\
\hline
\end{tabular}

${ }^{a}$ Reported in Chilean pesos (Ch.\$).

${ }^{\mathrm{b}}$ Reported in minutes.

\section{Empirical results}

\section{A. Logit estimates}

Estimates of the logit model of the probability of choosing preferred providers are reported in Table 4. It must be noticed that the parameters, like those of any non-linear model, do not necessarily have the partial derivative interpretation [see Greene (1997)]. In a binary model, the marginal effect of a change in a particular variable is simply a positive constant (the density function of the appropriate cumulative distribution function) times the relevant coefficient. Following Hopkins and Kidd (1996), the sign and relative size of the coefficients are informative.

\section{Table 4}

\section{Logit estimates for the choice of preferred providers}

$\begin{array}{llll}\text { Number of observations } & =1,904 & \chi^{2}[13] & =907.95 \\ \text { Prob }>\text { chi } 2 & =0.000 & \text { Log Likelihood } & =-835.25 \\ \text { Pseudo } \mathrm{R}^{2} & =0.35 & & \end{array}$

\begin{tabular}{|l|c|c|c|c|}
\hline & COEFFICIENTS & STD. ERRORS & $\mathrm{Z}$ & $\mathrm{P}>|\mathrm{z}|$ \\
\hline Constant & $7.4137^{*}$ & .6497 & 11.410 & 0.000 \\
\hline Age & $0.0087^{* *}$ & .0042 & 2.062 & 0.039 \\
\hline Gender & $0.6569^{*}$ & .1415 & 4.639 & 0.000 \\
\hline Primary school & -0.0498 & .2060 & -0.242 & 0.809 \\
\hline
\end{tabular}




\begin{tabular}{|c|c|c|c|c|}
\hline $\begin{array}{l}\text { Primary \& secondary } \\
\text { school }\end{array}$ & $0.6244^{* *}$ & .2428 & 2.571 & 0.010 \\
\hline Professional training & 0.9726 & .6019 & 1.616 & 0.106 \\
\hline University degree & $1.1374^{* *}$ & .4704 & 2.418 & 0.016 \\
\hline Employment status & $0.5933^{*}$ & .1615 & 3.674 & 0.000 \\
\hline Income & $3.45 \mathrm{e}-06^{*}$ & $1.04 \mathrm{e}-06$ & 3.334 & 0.001 \\
\hline Number of children & $-0.2200^{*}$ & .0595 & -3.697 & 0.000 \\
\hline Number of adults & $0.1033^{* * *}$ & .0561563 & 1.840 & 0.066 \\
\hline Zone of residence & $0.2361^{* * *}$ & .1359326 & 1.737 & 0.082 \\
\hline$R C M C^{\mathrm{a}}$ & $-0.0069^{*}$ & .0003861 & -18.116 & 0.000 \\
\hline Waiting time & $-0.0016^{* *}$ & .0008200 & -2.015 & 0.044 \\
\hline
\end{tabular}

${ }^{\text {a }}$ Relative cost of medical consultations.

* Significant at 1 percent.

** Significant at 5 percent.

*** Significant at 10 percent.

$L(0):-1,289.2317$

$L(\beta):-835.2577$

$-2[L(0)-L(\beta)]=907.95(22.36)$

Where $L(0)$ and $L(\beta)$ are the log-likelihood value for a model with an intercept only and the intercept and all covariates respectively.

The model presents a relatively good fit as indicated by the Pseudo $\mathrm{R}^{2}$ of 0.35. As a whole, the model confirms the a priori expectations. Among the variables reflecting individuals' attributes age, gender, employment status and income are positive and well defined. The pattern of coefficient signs for the set of dummies accounting for education are the expected but less well defined. The two variables for individuals' family composition are also well defined. The negative coefficient obtained for the number of children was the expected according to our hypothesis.

The variables accounting for individuals' access proved to be relevant determinants of individuals' choice. As we expected, the relative cost of medical consultations has a negative effect on the choice of preferred providers. On the other hand, the unexpected negative coefficient for waiting time could be indicating certain level of captivity of public insured to purely public provision. In what follows we analyse the results for each group of variables separately. 


\section{a. INDIVIDUALS' ATTRIBUTES}

To characterise each individual we used two demographic variables, age and sex, and three socio-economic variables, education, employment status and income. According to Hershey et al. (1975) demographic attributes do not have a clear theoretical place in utilisation models (whatever be the measure of utilisation). However, they have proved to be important factors in many of the studies focused on the choice of health care providers [Dor, Gertler and van der Gaag (1987), Gertler, Locay and Sanderson (1987), Gertler and van der Gaag (1988)]. Based on this background and on the discussion of section 3., we supported the inclusion of individuals' demographic attributes in our analysis.

As we hypothesised, there is a positive and statistically significant relation between the choice of preferred providers and age. This fact can be explained considering both the relatively higher opportunity cost of time during the most productive years and the increase in the time spent consulting doctors as medical needs increase with age (usually from the sixties onward). ${ }^{25}$ In the first case, the perspective of having to wait in person for long hours in a queue to consult a doctor certainly has a higher opportunity cost of time. Therefore, the possibility of jumping the queue by choosing preferred providers should be attractive. In the second case, even though the opportunity cost of time decreases (as individuals get retired and become pensioners face a reduction in income), the medical needs and time spent consulting doctors increase. As before, the perspective of queuing for long hours to be seen by a doctor at an advanced age should not be very welcomed. In this context, it would be reasonable to expect that individuals are willing to avoid the long queues found in public facilities and decide to demand preferred providers.

The positive and strongly statistically significant coefficient for gender clearly indicates that females are more likely to choose preferred providers than males. As many studies have shown, females tend to

${ }^{25}$ Grossman (1972a, 1972b) introduced a model where health is considered as a stock that depreciates as age increases. As the stock of health diminishes, individuals must invest more time and resources to partly avoid depreciation. 
demand more health services than males and, consequently, to spend more time consulting doctors. According to Lewis and Lewis (1977), women make 1.5 times more visits to doctors than males do. Furthermore, females not only must spend time consulting themselves but also must spend time when their children need to visit a doctor. These facts suggest that females should be relatively more concerned about queuing for attention than males. This argument, which is open to debate, certainly goes in an opposite direction with respect to the presumed higher opportunity cost of males. Two elements are usually invoked in order to provide the basis for this presumption: first, the higher participation rate of males in the labour market and, second, the higher wages enjoyed by males. However, since Becker (1965) it has been suggested that females would not participate in the labour market at the same rate as males because their opportunity cost of time out of the labour market (typically at home caring for their children and producing other goods) would be higher than the market wage rate. Following this reasoning, it would not be possible to assume, simply, that males have a higher opportunity cost of time than females. Therefore, the point that females should be more concerned about queuing for medical attention is a clear possibility. ${ }^{26}$

The pattern of coefficient signs and significance of the dummy variables accounting for the educational level, as a whole, tend to confirm the hypothesis that more educated individuals should be more likely to choose preferred providers. Education is probably to have both a direct and indirect effect on the choice of providers. ${ }^{27}$ The direct effect can be related to the notion that more educated individuals could value more the greater level of information about their medical condition and its treatment provided by preferred providers (one of the attributes associated to a more consumer-oriented environment). The indirect effect of education is its impact on income. According to the human capital theory, education and income are positively correlated. A higher income increases the opportunity cost, which would make less attractive the long queue to consult a public doctor and, therefore, more attractive the possibility to

\footnotetext{
${ }^{26}$ However, after controlling by income and education, the more or less willingness to queue may be just a matter of preferences.

${ }^{27}$ The role of education in health decision-making has been well documented by Grossman (1972a, 1972b) and Muurinen (1982).
} 
access preferred providers.

Certainly, education could become more relevant depending on the type of medical services considered. We developed the analysis using general medical consultations, which are commonly initiated by the individual according to his own perception and knowledge about the health problem detected. However, education should be less important in the case of follow-up visits and other health services like hospitalisations and surgeries. Doctors induce most follow-up visits while their opinions and recommendations are the relevant information for hospitalisations and surgeries.

Employment status and income reflect the opportunity cost of time of individuals. While unemployed and low-income individuals could be willing to spend more time in a queue, employed and high-income individuals could put a higher value on time and, consequently, seek to avoid the queue by choosing preferred providers. Our estimates for employment status and income show that both employed and high-income individuals are more likely to choose preferred providers. The estimate for income is particularly interesting because one could argue that the positive effect of income on the choice of preferred providers is simply the result of the copayment structure presented in Table 1. Clearly, the relative cost of medical consultations decreases as income increases. However, individuals' monthly monetary income and the relative cost of medical consultations present a low correlation (-0.12). This would indicate that the income ranks used to classify public insured do not necessarily represent their relative position in the overall income distribution. This fact could be the result of a deliberate policy by the government to ensure low copayments for most of the public insured.

b. INDIVIDUALS' FAMILY COMPOSITION

In order to capture the effect of individuals' family composition on the choice of preferred providers we included two variables: number of children and number of adults. Both variables are statistically significant. The negative coefficient for the number of children was the expected. Ceteris paribus, as the family size increases, each family member should be less likely to choose preferred providers and their associated higher cost. Probably, this fact reflects the equivalent income effect in the sense 
that larger households may have a lower standard of living than smaller households with the same income. Given that we assumed no differences in the quality of treatment between alternatives, the choice of purely public provision could become more probable as the family size increases. Conversely, the positive sign for the number of adults indicates that, ceteris paribus, individuals in families with more adults supporting the family budget should be more likely to choose preferred providers. However, the positive sign in this case says nothing about the differences in access that can emerge within the household depending on the importance that the family assigns to the "breadwinners". If "breadwinners" are considered more important, the family could be willing to let other members to queue.

\section{c. INDIVIDUALS’ ACCESS TO MEDICAL ATTENTION}

The main determinants of individuals' access to medical attention affecting the choice of preferred providers were hypothesised to be represented by individuals' zone of residence, the relative cost of medical consultations and waiting time. Individuals' zone of residence was included because most of the preferred providers are located in urban areas so urban residents should be more likely to chose preferred providers than rural residents. ${ }^{28}$ The result obtained confirms this presumption. Certainly, the location of preferred providers follows from the fact that both most of the Chilean population and most of the private hospitals, private clinics and private health centres are concentrated in urban areas.

The relative cost of medical consultations, measured as the relative value of copayments, was intended to capture the relative cost of getting medical care from preferred providers. The negative sign and strong significance of the coefficient for RCMC (relative cost of medical consultations) in Table 4, clearly show that the higher the relative value of

\footnotetext{
${ }^{28}$ The study of Scarpaci (1988) provides evidence on this point. In fact, in part of his study about the situation of the Chilean health sector in the 80 's, Scarpaci analysed the spatial distribution of doctors offering services as preferred providers in the Gran Santiago. He found that they tended to be concentrated in the Santiago Centro (Central Santiago), the heart of the urban area of Santiago.
} 
copayments the lower the probability of choosing preferred providers. This result is not surprising given the structure of copayments prevalent in the preferred provider system. Taking as a reference Table 1, the lower possible copayment to be paid for general medical consultations under preferred providers (corresponding to price level rating I) is 1.76 times higher than the higher copayment to be paid under purely public provision (the one paid by individuals classified in income group D). This notorious difference in copayments acts as a deterrent to the choice of preferred providers. Even thought we only used general medical consultations in the analysis, the extension to other medical services is likely to produce the same result. If the relative higher cost of a relatively affordable medical service like general medical consultations constitutes a deterrent to the choice of preferred providers, one should expect the same for more expensive medical services. A clear indicator of this presumption is given by the greater number of medical services of each type delivered under purely public provision (see Table B in the Appendix for the relevant figures).

Finally, CASEN 1992 included a specific question to evaluate the performance of public health centres in terms of waiting time. Individuals were asked about the time waited the last time they visited a public health centre. Unlike other questions in the health module, this particular question was not referred to a specific period of time. Basically, the aim was to capture individuals' past experiences with public health centres independently if they reported having visited a preferred provider during the last months preceding the survey. The reported waiting time at public health centre was, therefore, used to estimate the effect of the higher waiting time prevalent under purely public provision on the choice of preferred providers. The negative sign for the coefficient of waiting time in Table 4 was unexpected. However, from this result emerges an important point that has been studied, among others, by Propper (1993): the possibility of captivity. Basically, it is recognised that a subset of individuals may not have choice over all possible alternatives, say because of geographical location, lack of resources, etc. Such individuals are denoted captive to a particular option. In our model, and given the result obtained with waiting time, one could tentatively suggest that those individuals that are willing to spend long hours queuing to consult a doctor 
could have either a lower opportunity cost or, alternatively, they could be captive to the public sector. Certainly, captivity could be more likely for health services that are not available from preferred providers (notably emergencies). Clearly, the existence of a dominant public supplier implies that the services offered by preferred providers are to a large extent delineated by the activities of the public provider. Thus, one could expect that captivity would vary depending on the type of health services demanded.

Although captivity is an interesting element to be considered in explaining the negative sign for the coefficient of waiting time, the data utilised in our study do not permit to test this point.

\section{B. Sensibility analysis}

Tables 5 and 6 report results of the effect of changes in the explanatory variables on the probability of choosing preferred providers. This analysis was undertaken to complement our results of Table 4. Changes for each regressor were introduced holding the rest of the variables at their mean values. Table 5 shows the effects on probability of changes in individual and household attributes. Table 6 presents the effects on probability of changes in access variables.

In Table 5 we can see that the probability of choosing preferred providers increases with age. An individual of 30 years has a probability of 0.41 to choose preferred providers. This probability rises to 0.45 for an individual aged 50 and rises to 0.50 for an individual aged 70 . As age increases individuals seem to be less likely to be willing to queue for consulting a doctor and, accordingly, they seem to be more likely to be willing to pay for the higher cost of preferred providers in order to avoid waiting in a queue.

Table 5

Probability of choosing preferred providers: the effects on probability of changes in individual and household attributes. 


\begin{tabular}{|c|c|}
\hline PREDICTED PERCENTAGE CHOOSING & 0.41 \\
\hline \multicolumn{2}{|l|}{ Age (years): } \\
\hline 30 & 0.41 \\
\hline 40 & 0.43 \\
\hline 50 & 0.45 \\
\hline 60 & 0.48 \\
\hline 70 & 0.50 \\
\hline \multicolumn{2}{|l|}{ Gender: } \\
\hline Female & 0.52 \\
\hline Male & 0.36 \\
\hline \multicolumn{2}{|l|}{ Education: } \\
\hline No education & 0.23 \\
\hline Primary school & 0.45 \\
\hline Primary \& secondary school & 0.56 \\
\hline Professional trainee & 0.68 \\
\hline University degree & 0.71 \\
\hline \multicolumn{2}{|l|}{ Employment status: } \\
\hline Employed & 0.55 \\
\hline Not in the labour market & 0.40 \\
\hline \multicolumn{2}{|l|}{ Income (Chilean \$): } \\
\hline 40,000 & 0.44 \\
\hline 80,000 & 0.48 \\
\hline 160,000 & 0.54 \\
\hline 320,000 & 0.67 \\
\hline 640,000 & 0.86 \\
\hline \multicolumn{2}{|l|}{ Number of children: } \\
\hline 0 & 0.51 \\
\hline 1 & 0.45 \\
\hline 2 & 0.40 \\
\hline 3 & 0.35 \\
\hline 4 & 0.30 \\
\hline \multicolumn{2}{|l|}{ Number of adults: } \\
\hline 1 & 0.43 \\
\hline 2 & 0.45 \\
\hline 3 & 0.48 \\
\hline 4 & 0.51 \\
\hline 5 & 0.53 \\
\hline
\end{tabular}

The result for the condition female/male shows that the probability of choosing preferred providers by females is 1.44 times that of males. From this fact, it is clear that the notion of a higher opportunity cost of time of 
males is not necessarily applicable in the context of the demand for medical care. Females tend to use more medical services and tend to spend more time consulting doctors than males. Therefore, females should also tend to put a higher value on the time devoted to obtain medical attention.

The education level achieved by individuals importantly affects the probability of choosing preferred providers. While the probability for individuals with no education is 0.23 , individuals with professional trainee and university degree have probabilities of 0.68 and 0.71 , respectively. The well-documented positive correlation between education and income helps to explain why individuals with higher education levels are in a better position to demand consultations from the relatively more expensive preferred providers.

The set of probabilities for employment status and income confirms that employed and high-income individuals have a higher probability of choosing preferred providers. Employed have a probability of 0.55 while those who are not in the labour market have a probability of 0.40 . At the same time, the probability of choosing preferred providers increases from 0.44 for individuals with a monthly monetary income of Ch. $\$ 40,000$ to 0.86 for those with a monthly monetary income of Ch. $\$ 640,000$.

The number of children and the number of adults have opposite impacts on the probability of choosing preferred providers. As the number of children in the household increases, the probability of choosing preferred providers decreases. Individuals belonging to households with no children have a probability of 0.51 , while those belonging to households with 3 and 4 children have a probability of 0.35 and 0.30 , respectively. Conversely, as the number of adults increases, the probability of choosing preferred providers increases. The probabilities range from 0.43 for individuals belonging to households with one adult to 0.53 for individuals belonging to households with 5 adults.

On the other hand, and according to Table 6, individuals living in rural areas and those who have experienced long hours in a queue at public health centres have a lower probability to demand preferred providers. In the first case, the tendency of preferred providers to cluster in urban areas turns more difficult the access for individuals living in rural areas. 
Likewise, those having waited long hours in a queue at public health centres could also be those with a lower opportunity cost or they may be captive to public sector provision. They face, therefore, a lower chance to switch from public provision to preferred providers. In this context, the higher relative value of copayments constitutes an important deterrent to access preferred providers. This can be appreciated in Table 6 where the probability of choosing preferred providers strongly decreases from 0.99 to 0.22 as the relative value of copayments increases from Ch. $\$ 380$ to Ch. $\$ 1,430$, respectively.

Table 6

Probability of choosing preferred providers: the effects on probability of changes in access variables.

\begin{tabular}{|c|c|}
\hline PREDICTED PERCENTAGE CHOOSING & 0.41 \\
\hline \multicolumn{2}{|l|}{ Zone of residence: } \\
\hline Urban & 0.47 \\
\hline Rural & 0.41 \\
\hline \multicolumn{2}{|l|}{$R C M C(\text { Chilean } \$)^{\mathrm{a}}$ : } \\
\hline 380 & 0.99 \\
\hline 630 & 0.98 \\
\hline 880 & 0.93 \\
\hline 930 & 0.90 \\
\hline 1180 & 0.62 \\
\hline 1430 & 0.22 \\
\hline \multicolumn{2}{|l|}{ Waiting time (in minutes): } \\
\hline 30 & 0.50 \\
\hline 60 & 0.49 \\
\hline 120 & 0.46 \\
\hline 180 & 0.44 \\
\hline 240 & 0.41 \\
\hline 300 & 0.39 \\
\hline 360 & 0.37 \\
\hline
\end{tabular}

${ }^{a}$ Relative cost of medical consultations. 


\section{Conclusions}

The analysis carried out in the previous sections was intended to provide some empirical evidence on the determinants of the choice of preferred providers among the publicly insured in Chile. Little evidence, if any, was available about the role of income and other variables reflecting individual's attributes, individuals' family composition and access to medical care in this decision process. Along this paper we examined these factors and estimated a model involving the expected utility gain that a public insured could derive by demanding medical care from preferred providers

From the results, four aspects are particularly worth to mention. In first place, the positive correlation between income and the probability of choosing preferred providers would suggest certain level of segmentation in the preferred provider "market". ${ }^{29}$ This segmentation is likely to be the result of the coexistence of two systems with a different structure of copayments. While health care services are guaranteed at a reasonable cost for all public insured through the public facility network, the access to preferred providers is limited by the higher value of copayments. Probably, a system where minima were guaranteed and additional services could be purchased freely would reflect in a more appropriate way the solidarity principle in which the Chilean public health system is based.

A second important point is derived by the effect of the relative value of copayments on the choice of preferred providers. If, as we mentioned before, there is no difference in the efficacy of treatment between the available options, the lower cost of medical attention in public facilities constitutes a strong incentive to seek public provision. The government, on the other hand, has importantly contributed to reinforce this behaviour by reducing the percentage of copayments according to income. $^{30}$ This policy, which could be consistent with the view of a

\footnotetext{
${ }^{29}$ The existence of certain level of segmentation in the preferred provider "market" is not only suggested by our estimates, but also by statistics on the choice of purely public provision and preferred providers among public insured by income deciles (see Table $\mathrm{C}$ in the Appendix).

${ }^{30}$ Since 1990 the reduction in copayments has been of 60 percent for public insured in income groups $\mathrm{C}$ and $\mathrm{D}$. The magnitude of this reduction, which has been accompanied by a positive real adjustment in price level rating 1 (the base to calculate
} 
reduced ability to pay of public insured, would be inconsistent with the offer of a preferred provider system. In fact, if public insured in income groups $\mathrm{C}$ or $\mathrm{D}$ are believed to have difficulties to deal with the already reduced value of copayments under purely public provision, then they should have more difficulties to afford the substantially higher copayments found under preferred providers, ceteris paribus.

The third point is associated with the effect of the rationing of health services via waiting time on individuals' choice. Most of the opinion polls conducted among public insured to evaluate their perception about the performance of the public health system have shown that public users are extremely critical to what is defined as an excessive waiting time. Particularly, waiting time at public health centres has been indicated as a major problem by public insured in Chile. ${ }^{31}$ As we made clear in the introduction, we focused the analysis of public insured choice on general medical consultations, which are mainly provided at public health centres under purely public provision. In this context, if the negative sign of the coefficient for waiting time at public health centres is seen as an underlying response to certain degree of captivity of public insured to public provision, the issue of waiting time should turn more important as many public users have no real chance to take the option of preferred providers offered under the Chilean public health insurance system.

Finally, even though many studies carried out on diverse issues involving the demand of health care have treated the individual' maximising process in isolation, we followed a different approach by introducing some attributes of the family in our model. Several authors have suggested this approach. Basically, this strategy implies the recognition that many restrictions faced by individuals are better understood in the context of the family. In our analysis we used the number of children and the number of adults as variables affecting the resources available at individual level. Larger families (with more children) appear to be less likely to choose preferred providers, probably

copayments under purely public provision), has produced an increment in the relative cost of medical consultations making public provision more attractive.

${ }^{31}$ This pattern of criticism is different of what it is possible to find in countries like England where the main concern in public opinion is given by the length of waiting list. 
reflecting the equivalent income effect that larger households may have a lower standard of living than smaller ones with the same income.

\section{APPENDIX}

Table A

Income ranks by income groups (1992)

\begin{tabular}{|c|c|}
\hline INCOME GROUPS & $\begin{array}{c}\text { INCOME RANKS } \\
(\text { CHILEAN } \$)^{* *} 1992\end{array}$ \\
\hline $\mathrm{B}$ & $\leq 43,634$ \\
\hline $\mathrm{C}$ & $43,635-68,177$ \\
\hline $\mathrm{D}$ & $>68,177$ \\
\hline
\end{tabular}

* Income group A not included.

** The average observed exchange rate for 1992 was of Ch\$362.58 per US\$ 1 dollar.

Source: National Health Fund, Chile (Fondo Nacional de Salud, FONASA, Chile).

Table B

Number and type of health services delivered by provider per 100 beneficiaries (1994). ${ }^{*}$

\begin{tabular}{|l|c|c|c|}
\hline HEALTH SERVICES & $\begin{array}{c}\text { PURELY PUBliC } \\
\text { PrOVISION }\end{array}$ & PREFERRED PROVIDERS & TOTAL \\
\hline Medical visits $^{\text {a }}$ & 245.59 & 55.98 & 301.57 \\
\hline Diagnostic exams & 330.25 & 60.02 & 390.27 \\
\hline Clinical procedures & 8.25 & 35.29 & 43.54 \\
\hline Surgery procedures & 9.13 & 1.01 & 10.14 \\
\hline Hospitalisations & 80.28 & 6.95 & 87.23 \\
\hline Rest of services & 84.96 & 0.10 & 85.06 \\
\hline
\end{tabular}

${ }^{*}$ No figures available for 1992.

a Includes medical visits in patients' domicile, medical visits to hospitalised patients and medical visits in public health centres.

Source: Statistic Bulletin, National Health Fund, 1993-1994 (Boletin Estadístico, Fondo Nacional de Salud, FONASA, 1993-1994). 


\section{Table C}

Choice of provider by income deciles: percentages by columns (1992).

\begin{tabular}{|c|c|c|}
\hline INCOME DECILE & PURELY PUBLIC PROVISION & PREFERRED PROVIDERS \\
\hline 1 & 73.88 & 26.12 \\
\hline 2 & 75.18 & 24.82 \\
\hline 3 & 61.36 & 38.64 \\
\hline 4 & 62.20 & 37.80 \\
\hline 5 & 64.23 & 35.77 \\
\hline 6 & 49.62 & 50.38 \\
\hline 7 & 45.73 & 54.27 \\
\hline 8 & 31.96 & 68.04 \\
\hline 9 & 31.03 & 68.97 \\
\hline 10 & 22.22 & 77.78 \\
\hline
\end{tabular}

Source: author's calculations from the National Survey for Socioeconomic Characterisation (Encuesta Nacional de Caracterización Socioeconómica Nacional, CASEN 1992).

\section{REFERENCES}

ACton, J.P. (1975a). "Demand for Health Care Among the Urban Poor with Special Emphasis on the Role of Time". R-1151-OEO/NYC. Santa Monica, CA: Rand Corp.

(1975b). "Nonmonetary Factors in the Demand for Medical Services: Some Empirical Evidence". Journal of Political Economy 83: 595-614.

Akin, J.S., C. GrifFin, D.K. GuilKeY, and B.M. Popkin (1985). The Demand for Primary Health Services in the Third World. Totowa, N.J.: Rowan and Allenheld. 
BECKER, G.S. (1965). "A Theory of Allocation of Time". Economic Journal 75: 493-517.

Bitran, R., and D.K. MCInNes (1993). The Demand for Health Care in Latin America: Lessons from the Dominican Republic and El Salvador. Washington, D.C.: Economic and Development Institute, World Bank.

Dor, A., P. Gertler, and J. VAN DER GaAG (1987). "Non-Price Rationing and Medical Care Provider Choice in Côte d'Ivoire". Journal of Health Economics 6: 291-304.

Gertler, P., L. Locay, and W. SANDERSON (1987). "Are User Fees Regressive?" Journal of Econometrics 36: 67-88.

Gertler, P., and J. VAn Der GaAg (1988). Measuring the Willingness to Pay for Social Services in Developing Countries. LSMS Working Paper № 45. Washington, D.C.: World Bank.

GrEen, W.H. (1997). Econometric Analysis. Prentice-Hall, Inc.

Grossman, M. (1972a). The Demand for Health: A Theoretical and Empirical Investigation. National Bureau of Economic Research Ocassional Paper 119. New York.

(1972b). "On the Concept of Health Capital and the Demand for Health”. Journal of Political Economy 80: 223-255.

Hershey, J.C., H. Luft, and J. Gianaris (1975). "Making Sense Out of Utilisation Data". Medical Care 13, No 10: 838-854.

HOPKINS S., and M.P. KIDD (1996). "The Determinants of the Demand for Private Health Insurance under Medicare". Applied Economics 28: 1623-1632.

Judge, G.G., W.E. GRIFFITHS, R.C. HILl, H. LÜTKEPOHL, and T-C. LeE (1985). The Theory and Practice of Econometrics. New York: Wiley and Sons. 
The Determinants of the Choice of Preferred Providers among the...

LeOPOLD, J.R., and K.M. LANGwell (1978). "The Demand for Health Care with Special Emphasis on Cost Containment: A Review of the Literature", in National Commission on the Cost of Medical care, 1976-1977. Vol. 3. Chicago: American Medical Association.

LEWIS, C.E., and M.A. LEWIS (1977). "The Potential Impact of Sexual Equality on Health”. New England Journal of Medicine 297, № 16: 863-869.

Lindsay, C., and B. Feigenbaum (1984). "Rationing by Waiting Lists". American Economic Review 74 (3): 404-417.

McFadden, D. (1981). "Econometric Models of Probabilistic Choice", in C. Manski and D. McFadden (eds.), Structural Analysis of Discrete Data: With Econometric Applications. Cambridge, Mass.: M.I.T. Press.

Maddala, G. (1983). Limited Dependent and Qualitative Variables in Econometrics. Cambridge: Cambridge University Press.

MuURINEN, J.M. (1982). "Demand for Health: A Generalised Grossman Model". Journal of Health Economics 1: 5-28.

Propper, C. (1993). "Constrained Choice Sets in the U.K. Demand for Private Medical Insurance”. Journal of Public Economics 51: 287-307.

(1989). "An Econometric Analysis of the Demand for Private Health Insurance in England and Wales". Applied Economics 21: 777-792.

RICE, R. (1966). "An Analysis of the Hospital as an Economic Organisation". The Modern Hospital 106: 87-91.

SCARPACI, J.L. (1988). Primary Care in Chile: Accessibility Under the Military Rule. University of Pittsburgh Press.

Sindelar, J.L. (1982). "Differential Use of Medical Care by Sex". Journal of Political Economy 90: 1003-1019 
VAN DE Ven, W., and B. VAN PRAAG (1981). "The Demand for Deductibles in Private Insurance: A Probit Model with Sample Selection". Journal of Econometrics 17: 229-252. 